\title{
Acute MDMA Exposure Causes Reference Memory Impairments in the Radial Arm Maze with Rats
}

\author{
D.N. Harper*, C. Kay and M. Hunt
}

School of Psychology, Victoria University of Wellington, New Zealand

Keywords: MDMA, scopolamine, 8-arm radial maze, working memory, reference memory.

\section{INTRODUCTION}

Previous research has indicated that acute exposure to the recreational drug MDMA ('ecstasy') may impair memorytask performance because subjects confuse stable trialindependent elements of the memory task rather than via a

\section{METHODS}

15 rats were trained in an 8-arm radial maze task in which the same four arms were always baited with food at the start of a trial, with the four remaining arms never baited. Rats were permitted to make four arm visits before being

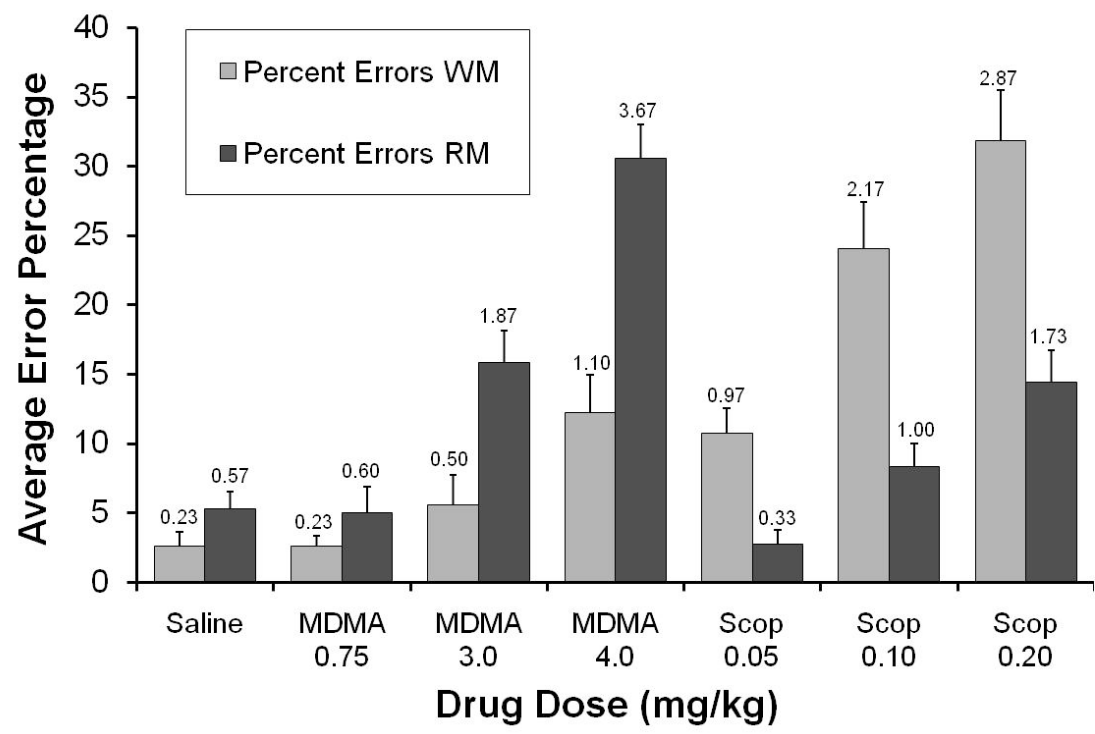

Fig. (1). Group mean error scores for Working $v s$ Reference Memory performance as a function of drug dose (MDMA vs Scopolamine) in Experiment 1.

disruption to working memory function [1, 2]. This possibility was examined using a version of the 8 -arm radial maze task with rats that is designed to separate working memory function from reference memory function [3]. In Experiment 1 the effects of MDMA were compared to the classic amnetic drug scopolamine (which has been shown to produce working memory deficits in the current radial arm maze task [4]). The effects of MDMA were also compared to the dopamine agonist GBR12909 and serotonin agonist citalopram (in Experiment 2) as well as the dopamine D2 agonist Quinpirole and the dopamine D1 agonist A68930 (in Experiment 3) in order to further examine the possible role of dopamine in an MDMA-induced performance deficit.

*Address correspondence to this author at the School of Psychology, Victoria University of Wellington, New Zealand; Tel: +64 44635561; Fax: +64 44635402; E-mail: david.harper@vuw.ac.nz removed from the maze. In this task visiting a 'never-baited' arm constitutes a reference memory error, whereas revisiting a previously baited arm within a trial is considered a working memory error. All rats had achieved a minimum $80 \%$ accuracy criterion after 25 sessions of training. After initial training rats were administered MDMA $(0.75,3.0,4.0$ $\mathrm{mg} / \mathrm{kg})$, scopolamine $(0.05,0.1,0.2 \mathrm{mg} / \mathrm{kg})$, or saline across different sessions in Experiment 1; GBR 12909 (10, 20, 30 $\mathrm{mg} / \mathrm{kg}$ ) or Citalopram $(15,30 \mathrm{mg} / \mathrm{kg})$ in Experiment 2; and Quinpirole $(0.08,0.12 \mathrm{mg} / \mathrm{kg})$ or A68930 $(0.3,0.9 \mathrm{mg} / \mathrm{kg})$ in Experiment 3. All drugs were administered i.p 15 minutes before the start of testing.

\section{RESULTS}

Using this task it was found that acute MDMA dosedependently caused a greater increase in reference memory errors compared to working memory errors. In contrast, and 
as demonstrated previously, a cholinergic antagonist (scopolamine) produced a greater impairment to working memory versus reference memory (see Fig. 1). The pattern of deficit produced by MDMA was also seen following administration of the dopamine agonists GBR12909, quinpirole \& A68930. That is, there was a dose-dependent increase in reference memory errors to a significantly greater degree than any increase in working memory errors. However, citalopram (a serotonin agonist) did not produce an increase in reference memory errors versus working memory errors.

\section{DISCUSSION \& CONCLUSION}

This study demonstrated that the memory impairment produced by MDMA in the radial arm maze task is best described as a 'reference memory' deficit. Furthermore, this pattern of impairment is also produced by specific dopamine agonists, but not by an acetylcholine antagonist or a serotonin agonist. Thus, it appears that the agonist dopamine actions produced by acute MDMA exposure [5] may be important in the reference memory-impairing effects of MDMA. One interpretation of this reference memory impairment is that rats are impaired at remembering longterm trial-constant task rules as opposed to trial-dependent information. However, an examination of the patterns of arm choices made, in conjunction with various clues from other human and non-human data [6], suggests that MDMAinduced reference memory impairments may be caused by an increase in 'localised perseverative response tendencies' following drug exposure.

\section{REFERENCES}

[1] Harper DN, Wisnewski R, Hunt M, Schenk S. (+/-) 3, 4methylenedioxymethamphetamine, d-amphetamine and cocaine impair delayed matching-to-sample performance via an increase in susceptibility to proactive interference. Behav Neurosci 2005; 119: 455-63.

[2] Harper DN, Hunt M, Schenk S (). Attenuation of the disruptive effects of (+/-) 3, 4-methylene dioxymethamphetamine (MDMA) on delayed matching-to-sample performance in the rat. Behav Neurosci 2006; 120: 201-5

[3] Olton DS, Papas BC. Spatial memory and hippocampal function. Neuropsychologia 1979; 17: 669-82.

[4] Wirsching BA, Beninger RJ, Jhamandas K, Boegman RJ, ElDefrawy SR. Differential effects of scopolamine on working and reference memory of rats in the radial maze. Pharmacol Biochem Behav 1984; 20: 659-62.

[5] Gerra G, Zaimovic A, Moi G, et al. Effects of (+/-) 3, 4-methylenedioxymethamphetamine (ecstasy) on dopamine system function in humans. Behav Brain Res 2002; 134: 403-10.

[6] von Geusau NA, Stalenhoef P, Huizinga M, Snel J, Ridderinkhof KR. Impaired executive function in male MDMA ("ecstasy") users. Psychopharmacology 2004; 175: 331-41 